\title{
The Performative Violence of the Wedding Dress: Teaching Queer Theory Through Object Orientation
}

Katie Beswick, Drama Department, University of Exeter

The ubiquity of the image is striking in its absolute sameness. White teeth, white dress, more often than not white woman. Sometimes, it is girls I haven't seen for fifteen or twenty years; girls who are now women, slimmed down and made-up, covered in white satin or lace or silk. Sometimes it is celebrities, or friends of friends, or royals - made as conventionally beautiful as they possibly can be for the consumption of the camera. These days the spouse is not always a man, though often there is a man in the photo somewhere, dressed in a dark suit that is invariably easier to move in than whatever the women are wearing. Not that you would sense discomfort from the image: in the image, the woman is almost always smiling.

This smile remains - despite what that white dress is doing to her body, and what it symbolises. The corset style of the popular strapless dress, restricting breath as it constricts the ribcage. The heavy skirt of the ballgown type 'princess dress' that tugs at the skin where waist meets bodice. The way the fitted, flared mermaid dress, that narrows until it spills out at the ankles, might cause the bride to trip over and fall flat on her face. The residual expectation of virginity, obedience and motherhood. The veil that conceals the woman underneath it, rendering her a homogenous bride.

Image 
How does the wedding dress perform violence?

This question is designed as a provocation to students of theatre and performance encountering queer theory for the first time. I have found that using objects as a way into queer theory is a generative method for encouraging performance students to reflect upon how cultures of heterosexuality, patriarchy and shame are sustained. It also offers methods for looking at performance and cultural objects 'queerly': that is conceptualising how bodies and objects are 'gendered, sexualised and raced' (Ahmed 2006: 5), in ways that are normalised and valourised so that they become part of the overarching hegemony through which culture operates.

The white wedding dress is a useful starting point for theatre students as it is at once an object, a costume and a symbol: it is drenched in meaning, desire, expectation. As the narrator in Angela Carter's novel The Magic Toyshop describes:

Symbolic and virtuous white. White satin shows every mark, white tulle crumples at the touch of a finger, white roses shower petals at a breath. Virtue is fragile. It was a marvellous wedding dress. (1967: 13)

Understanding the politics of the symbolism that immerses culture is essential for future artists and creative producers. Most students, from a range of backgrounds, arrive at University with some familiarity and unexamined existing feelings about white wedding dresses - thanks not only to the trope of marriage as resolution and happy ending in film, theatre and literature but also to the dominance of western (particularly US) culture on much of the world stage. 
For many of the students I teach, the goodness of marriage and therefore positive associations with wedding dresses are taken for granted - reinforced everywhere, but especially by recent successes in the struggle for equal marriage fought by gay rights activists and the widespread acceptance of marriage between gay and lesbian couples in the UK.

My own uneasy feelings about marriage and its attendant cultural symbols are often a site of disorientation for my students. I believe in using one's own feelings and experiences in the classroom as means of critically unfastening students from their orientations towards objects and ideas. Feeling differently from the dominant culture serves as a method for 'creating a new angle' (Ahmed 2006: 4), and inviting students to look from it. Of course, offering students access to any perspective that might unsettle their existing worldviews must be done in a way that creates room for disagreement and (difficult) feelings. It is also important to create critical distance by using theory as a scaffolding for thought and discussion.

In this respect, the following texts have proved useful in discussions around violence, patriarchy, sexuality, whiteness and marriage:

- Sarah Ahmed's Queer Phenomenology (2006), for introducing the concept of object orientation and connecting queer theory to phenomenology

- Jennifer Doyle's Doyle Hold it Against Me: Difficulty and Emotion in Contemporary Art (2013), for presenting difficult feelings a generative site for critical inquiry

- Eve Kosofsky Sedgwick's Touching Feeling: Afffect, Pedagogy and Performativity (2001), for a conceptual framework for understanding the 
relationship between our interactions with physical objects and our inner emotional word

- Greta LaFleur's article 'Heterosexuality without Women' (2019) [add hyperlink to https://blog.lareviewofbooks.org/essays/heterosexuality-without-women/], for considering the implications of whiteness in constructing heterosexuality and heterosexual desire

- Michael Warner's The Trouble With Normal (1999), for a critical position on the role of marriage in upholding inequalities through social and sexual control - John Gultang's (1969) concept of structural violence is also useful in offering students a way of thinking about the concept of violence beyond physical acts of aggression.

How does the wedding dress perform violence? is a question that might structure a seminar, presentation, essay or portfolio assignment.

I have found that asking students to use theory to construct an argument that might push against their deeply held feelings is useful not only in honing their critical skills, but also in helping them to clarify their own positions. Demanding a critical focus on obiects also encourages artmaking that is attentive to the relationships between thought and feeling generated through taken-for-granted symbolism. 